\title{
"Y YO TENÍA MIEDO MUCHO..." MÁS ALLÁ DE LA GRAMÁTICA EN LA CLASE DE ESPAÑOL COMO SEGUNDA LENGUA
}

\author{
Carlos Sánchez Avendaño
}

\begin{abstract}
RESUMEN
Este estudio analiza el desempeño narrativo oral de siete hablantes no nativos del español (HNN) comparándolo con el de una hablante nativa costarricense (HN). El análisis tiene como propósito observar la correlación entre la capacidad narrativa de un HNN y la percepción que tienen los hablantes nativos de su competencia comunicativa y su fluidez. Se parte de este análisis para formular algunos comentarios sobre el tratamiento tradicional de la gramática en la clase de español como segunda lengua.
\end{abstract}

\begin{abstract}
This study analyzes the narrative oral performance of seven nonnative Spanish speakers (NNS) comparing it with that of a Costa Rican Spanish native speaker. The analysis observe the co-relation between the narrative competence of NNSs and the perception which native speakers have about their communicative competence and fluency, in order to propose some commentaries concerning the traditional treatment of grammar in the Spanish as a Second Language class.
\end{abstract}

\section{Introducción}

En este estudio, se analiza el desempeño narrativo oral de siete hablantes no nativos del español (HNN), de nacionalidad suiza o alemana, comparándolo con el de una hablante nativa costarricense (HN). El análisis tiene como propósito observar la correlación entre la capacidad narrativa de un HNN y la percepción que tienen los hablantes nativos de su competencia comunicativa y su fluidez, para lo cual doce jueces costarricenses escucharon una historia de emoción contada por cada uno de los informantes y la evaluaron mediante una escala de 1 a 7 , con la forma de un diferencial semántico cuyos polos eran, en relación con la historia, "bien contada" o "mal contada". Se parte de este análisis para formular algunos comentarios sobre el tratamiento tradicional de la gramática en la clase de español como segunda lengua.

\section{Las historias de emoción como género narrativo}

Los discursos tienen ciertas formas típicas para organizar, formal y semánticamente, lo que se dice. El término "montaje" se refiere a la perspectiva desde la cual el hablante organiza 
su discurso e incluye la presentación total del texto, "que puede estar motivada por la intención de crear suspenso, de convencer al oyente de la verdad de lo que dice mediante la adición de detalles complementarios verosímiles (...), de maravillarle o sorprenderle" (Brown 1993: 185). Este complejo que determina la organización del texto crea expectativas en el interlocutor y los elementos tematizados restringen de algún modo la interpretación del resto (174). Los discursos, entonces, se pueden clasificar en géneros de acuerdo con las características que presentan.

La tarea lingüística que debían llevar a cabo los HNN de este estudio ${ }^{1}$ era hablar sobre una vez en sus vidas en que hubieran experimentado cada una de las emociones que se les presentaban en fichas mediante las etiquetas miedo, enojo, felicidad/alegría, vergüenza, culpa y tristeza. Parece ser que, cuando se les pide a las personas que lleven a cabo este tipo de tarea, sus respuestas tienen, en la mayoría de los casos, la forma de una historia o narración (Rintell 1990: 81). Esto se comprende si se analizan las funciones de las narraciones: dotar de sentido a las experiencias (82), hacer que las experiencias personales se ajusten a la manera en que la cultura exige que se codifiquen (contando la historia varias veces y reelaborándola para proporcionarle mayor coherencia), presentar al narrador desde una perspectiva específica (como víctima o como héroe), convertir los acontecimientos pasados en algo más tangible (como cuando se narra un hecho histórico) y establecer relaciones interpersonales con un grado mayor de intimidad (McCabe 1999: 315). Labov (Rintell 1990: 82) señala que el objetivo principal de las narraciones podría ser facilitar un marco para la evaluación de lo sucedido de parte de los interlocutores: contar una historia y evocar el sentimiento o la emoción por la que atravesamos, ayuda al hablante a enfrentarse a la experiencia y recibir retroalimentación (apoyo, admiración, compasión, etc.) de parte de sus interlocutores.

El género discursivo que se esperaría que utilizaran los HNN, por lo tanto, sería el narrativo; es decir, el género en que se codifican los recuerdos de las experiencias por las que pasamos. Específicamente, deberían ser narrativas personales, en otras palabras, un recuento de los acontecimientos que tienen una relevancia inmediata para el narrador, puesto que forman parte de su vida. De hecho, para Labov (1999: 225), la "narrativa es un método de recapitular la experiencia pasada asociando una secuencia verbal de cláusulas con una secuencia de acontecimientos que, según se infiere, ocurrieron realmente". Otro requisito importante es que los narradores deben formular su historia de manera que resulte relevante para los oyentes (Bonvillain 1993: 298). Como tipo de discurso, las narraciones tienen algunas características formales: contienen información descriptiva (la ubicación temporal y espacial de los acontecimientos), evaluaciones (comentarios sobre las emociones experimentadas y la reacción de los participantes) e información sobre las diversas secuencias de la historia (McCabe 1999: 315).

Se han desarrollado especies de "gramáticas de la narración” para dar cuenta de la estructura de este género. Un modelo de análisis propuesto para estudiar la organización de una narrativa es el de Labov (Labov 1999, Rintell 1990: 82, Bonvillain 1993: 298). Según este lingüista, la estructura de las narraciones sobre experiencias personales presenta los siguientes componentes:

1. El resumen: resumen general de la historia sobre el acontecimiento en su totalidad, el hecho principal o el resultado: ¿de qué se trata?

2. La orientación: escenario de la historia e información de segundo plano (tiempo, lugar, personajes, situación o actividad): ¿quién?, ¿cuándo?, ¿qué?, ¿dónde? 
3. La evaluación: medio utilizado por el narrador para indicar el punto de la narrativa, la razón para haberla contado. En el caso de las historias de emoción, la evaluación se refiere a las actitudes y emociones del narrador o los personajes al experimentar el suceso: ¿y qué?

4. Las cláusulas narrativas o la acción: recuento de los acontecimientos en orden cronológico. Estas cláusulas narrativas son el esqueleto de la historia: ¿entonces qué pasó?

5. El resultado o resolución: lo que pasó después de todo, la resolución del conflicto: ¿qué pasó al final?

6. La coda: señala el final de la historia (por ejemplo, "así fue").

Los dos únicos requisitos indispensables para que un discurso narrativo se pueda considerar como tal son la acción y la resolución, los demás son facultativos. No obstante, "una narración completa comienza con una sección de orientación, continúa con el complejo de acciones o eventos, se suspende para mostrar la evaluación antes de la resolución, termina con el resultado, y regresa al oyente al tiempo presente con la coda" (Labov 1999: 234).

\section{Las historias de emoción contadas por los HNN y por la HN}

En este trabajo, se parte del supuesto de que la capacidad narrativa del hablante y el considerar la historia como "bien contada o "mal contada" están, en gran medida, determinados por la complejidad estructural de las narraciones, por lo que, seguidamente, se presenta un análisis pormenorizado de cada una de ellas. Se sigue, para este fin, el modelo de Labov.

También resulta útil observar el empleo discursivo que los HNN hacen del pretérito perfecto simple y del pretérito imperfecto de indicativo. Ambos tiempos pertenecen a la esfera del mundo narrado, es decir, los tiempos que empleamos para indicarle al oyente que vamos a contar un relato (Weinrich 1964: 67), pero cumplen funciones distintas. El imperfecto sirve para indicar la escenografía de la narración, el plano de fondo (ubicación temporal y espacial, las descripciones) donde tienen lugar los acontecimientos sucesivos que hacen avanzar la historia. Estos acontecimientos aislados se expresan en pretérito perfecto simple (Alar$\cos$ 2000: 162).

Por último, y con el afán de determinar si la historia proporciona la información necesaria para asociar los acontecimientos con la emoción que motiva el relato, se dice si cumple con los argumentos básicos de cada sentimiento, según la propuesta de Marina (1999) y se aclara cuáles son estos argumentos.

\subsection{La historia de emoción del HNN $\mathbf{1}^{2}$}

a. HNN: hace dos meses o algo / cuando estuve en Jacó /// -ahhh- nosotros queríamos ir a la por la playa / por las /-uhhh- no sé son / cammm / no son no es / playa de de / son de era una pla estaba era una playa de piedras / y // -eeeee- no / -ahhhhhh- pudi no /-ahhhhhh- no pudimos pasar / porque era una ¿cómo se llama?/ un una /-uhhhhh- /un cue cue /-ummm- una cueva / una cueva entre / no pudimos pasar porque tres meses tres metros 
del mar / entonces queríamos //-ammmmmmm- subir / en la / 111 en la en 11 las montaña // y / hace / era muy muy / ¿cómo se dice? / muy

$\mathrm{HN}$ : muy empinado

HNN: muy empinado / y // -ehh- -ahh- después /// -ahhh- cuatr cuarentas metros no yo vi que no se puede / -eehhhh- o que no tiene sentido // -amm- subirse más /y yo vi / -ehhatrás y vi cuántos metros son y que es muy difícil regresar y también es muy difícil / -ah- subirse y lo que // -ammm- lo que hizo las cosas / -am- también muy //-mmmm- muy midoso [miedoso] era que las las las /-mmmmm- piedras / no eran fijadas está / entonces yo pensaba cuando yo me sube 'ah, son fijadas' pero no eran fijadas por entonces cualquier momento algo / se cayó y yo te tenía miedo mucho

HN: ¿y al final qué hicieron? ¿Subieron o ...?

HNN: al final yo me /yo // -ehhhh- bajó / yo bajó

1. Resumen: su historia no presenta esta parte.

2. Orientación:

a) Temporal: hace dos meses.

b) Espacial: Jacó (la playa).

c) Personajes: el narrador y otros no especificados.

d) Descripción del espacio: la playa era de piedras, la cueva estaba a tres metros del mar, la montaña era muy empinada, las piedras no estaban fijas.

3. Evaluación: "y yo tenía miedo mucho"

4. Secuencias de la acción:

a) Los personajes querían ir a la playa.

b) No pudieron pasar porque había una cueva.

c) Querían subir la montaña.

d) Se dieron cuenta de que no podrían porque era muy alto.

e) Se dieron cuenta de que era difícil regresar y también seguir.

f) Se dieron cuenta de que las piedras no estaban fijas y que se podían caer.

5. Resultado y coda: El narrador bajó.

Como se puede apreciar, la narración de este hablante presenta la mayoría de los componentes, con excepción de los más periféricos (el resumen) y comprende los argumentos propios del sentimiento de miedo ${ }^{3}$. Su uso de los tiempos del mundo narrado es totalmente adecuado, con excepción de la forma 'se cayó', que no forma parte de los hechos que tuvieron lugar, sino de los posibles, y por eso no se justifica su empleo en pretérito simple.

\subsection{La historia de emoción del HNN 2}

b. HNN: -ehhhh- una vez en mi trabajo // tenía una una señora co /-ehhh- / de noventa y ocho años / y yo le / preguntó pregunté de apagar el luz / y ella ella sopló porque ella creía que son candeles

HN: ¡ah! ¿en serio?

HNN: sí 
HN: ay qué linda

HNN: [sopla]

HN: ¿y qué?

HNN: y no // -ehhhh- no podría ¿no?

HN: ajá

HNN: por eso era muy // muy divertido / este situación

$\mathrm{HN}$ : ¿y ella rió también?

HNN: ¿perdón?

HN: ¿ella se rió también?

HNN: no porque ella no realiza que / realizó que era como // para apagar con / los botones / ella cre /-ehhh- era en el / la época anciana

1. Resumen: no hay.

2. Orientación:

a) Espacial: el lugar de trabajo.

b) Personajes: la narradora y una señora de 98 años.

3. Evaluación: "por eso era muy divertido"

4. Secuencia de acontecimientos:

a) La narradora le pidió a la anciana que apagara la luz.

b) La anciana sopló porque creía que eran candelas.

c) La anciana no pudo apagar la luz.

d) La anciana no se dio cuenta de que se apagaba con un botón.

5. Resultado: La anciana no pudo apagar la luz.

6. Coda: no hay.

La historia de esta HNN cumple también con la mayoría de las partes, pero no hay un resultado claro. Sin embargo, se puede inferir de la historia que el final es que la anciana no pudo apagar la luz.

El uso de los tiempos del mundo narrado es adecuado, con excepción de la forma 'podría' en lugar de 'pude'. Aunque la emoción llevaba la etiqueta de felicidad/alegría, la hablante contó más bien una historia de cuando tuvo una experiencia divertida y por eso no cumple con todos los argumentos de la emoción original ${ }^{4}$, pero sí cuenta con éxito una historia sobre un momento gracioso.

\subsection{La historia de emoción del HNN 3}

c. HNN: que tenía / -eh- tenía dos mi mis uno de mis mis más // uno de mi culpa más grande fue // cuando yo / pero en Suiza tú tienes que hacer / tú tienes que ir al militario ¿no? /// tú tienes que es es la ley es el ley / y el ley dice. con trein con veinte años tú tienes que hacer por diecisiete / -ehh- semanas / una unas una // una una treinin [training 'entrenamiento'] /un entrenado por diecisiete años y después / hasta tú tienes trescientos días tú tienes que ir todo el año / por tres semanas //hasta hora ahora es cuaren cuarenta y dos años/ tú tienes que ir / todo el año todos los dos años por tres semanas /oquey/ y con dieciocho años tú tienes que 
decidir qué tú quieres / qué qué tú / qué tú quieres //-ehhh- -mmm-/ hay diferente grupos en el militario ¿no?/ hay de ¿cómo se llama? yo no puede decir en español hay /hay infantería hay artilería hay / otras cosas y tú tienes que decir qué tú quieres / y tú tienes que hacer un un testo de deporte /tú tienes que hacer un como un testo de / pequeño examen de gramá de de alemán pero quieren saber / si tú eres una ton una gran tonto o no un gran tonto /más o menos /quieren de gen quieren un poco verificar qué tú / qué persona tú eres ¿no? y oquey yo yo yo esto en el ///-ehhh- con dieciocho años yo / yo / yo ha hecho eso yo yo / ¿cómo? hacer yo hago yo hagué esto hacer ////-ehhh- ¿cómo es el pasado indefinido // de hacer? /// he //¿cómo es? dime

$\mathrm{HN}$ : ¿hice?

HNN: hice ya yo hice // este este examen en deporte /-eh- el resto / no no fue difícil claro que no / pero // yo fue muy bien en el deporte y yo quie yo piensé que // que / cuanto hago hay algo bueno / en el militario /que que tenía mucho cambios y mucha posibilidades / yo quiero ir en una /una grupo de elito ¿cómo se llama esa? /-ehh- en tenía elitos tenimos ten ten tenemos grupo elitos también /es y yo me. /// -eh- yo yo yo // yo tomé una un grupo de elito pero yo fue buen en deporte y no soy una tonto y tenía e ellos dicen 'oquey tú puedes ir' // y yo dije que eso es fue mi / mi / culpa increíble una gran culpa // no no no culpa / un falta.

1. Resumen: se comienza un resumen de la historia, pero se deja incompleto: una de sus culpas más grandes fue cuando

2. Orientación:

a) Información necesaria para comprender la historia: Esta sección ocupa una buena parte de la historia, pero es poco clara. El hablante falla en repetidas ocasiones en dejar en claro cuál es la situación en su país y varias veces rectifica los datos, lo que hace que la comprensión sea más difícil: en Suiza es obligatorio hacer servicio militar a los veinte años por diecisiete semanas. Posteriormente, dice que hay que hacer un entrenamiento por diecisiete años y que es necesario asistir hasta completar trescientos. Luego dice que hay que ir todo el año por tres semanas y que hasta ahora son cuarenta y dos años. Finalmente, repite que es necesario ir cada dos años por tres semanas. Agrega que a los dieciocho años hay que decidir qué se quiere hacer, pues hay diferentes grupos en el ejército: infantería, artillería, etc., y, asimismo, es necesario hacer exámenes de deportes y de alemán, con el fin de probar que no se es un tonto y ver qué tipo de persona se es. Como se mencionó antes, esta parte introductoria resulta sumamente confusa.

b) Ubicación temporal: cuando el narrador tenía dieciocho años.

3. Evaluación: La evaluación se sitúa al final de la historia, pero en lugar de servir como explicación y darle sentido a la narración como un todo, lo que hace es confundir más al oyente, pues el mismo narrador no está claro en cuál es la emoción que corresponde a lo que relató: "eso es fue mi mi culpa increíble una gran culpa // no no no culpa / un falta".

4. Secuencia de acontecimientos:

a) A los dieciocho años él tuvo que seguir el proceso para entrar al ejército. Esta parte se relata con mucha dificultad, pues una buena porción del tiempo se pierde en la conjugación de un verbo en pretérito perfecto simple.

b) Él pensó que podía haber algo bueno en todo lo que hiciera. 
c) Él quería entrar a un grupo de élite. Esta parte también resulta muy confusa, pues no queda claro a qué se refiere el narrador (especialmente por problemas de léxico) y el hilo de la historia se pierde por completo. Nuevamente hay referencias de información, pero estas, lejos de contribuir a aclarar la historia, la hacen más oscura: explicación de que existen grupos de élite y que el narrador era bueno en deporte y no era tonto.

d) La gente del ejército le permitió entrar a uno de estos grupos. Esta parte se deduce de la lectura atenta de la historia, pues no es fácil comprender a qué se refiere el permiso. También hay un problema de cohesión al referirse a un 'ellos' sin nunca haber introducido al referente específico.

5. Resultado: no hay ningún resultado claro.

6. Coda: decir que esa situación fue su culpa.

Como queda evidenciado en el análisis, este hablante tiene serios problemas para cumplir con los requisitos discursivos del género narrativo. Primero, intenta un resumen preliminar, pero lo deja sin acabar, lo que da desde el principio una sensación de pérdida. Segundo, trata de preparar el terreno en forma bastante extensa con la información sobre el funcionamiento del ejército en su país para luego contar la historia, pero esta sección es poco clara y mucho más larga que la secuencia de eventos. Tercero, la secuencia de acontecimientos no lleva a ninguna parte, no se sabe qué es lo que pasó ni estos parecen contribuir al hilo narrativo. Cuarto, la evaluación (que además sirve como coda) no se formula en términos claros. No se entiende por qué el narrador se sintió culpable, pues en la historia no se exponen los argumentos que acompañan a esta emoción ${ }^{5}$. Además, el mismo hablante percibe esta incongruencia al señalar al final que no se trata de una culpa, sino de una falta. Tampoco es claro por qué. Quinto, no hay un resultado en la historia y tampoco resulta fácil deducirlo.

El uso de los tiempos del mundo narrado no es adecuado. Se utiliza el presente para el segundo plano de eventos en el pasado y el pretérito simple no marca en algunos casos una línea narrativa.

\subsection{La historia de emoción del HNN 4}

d. HNN: ahhh- en particular /me recuerdé excelente de una situación que tenía hoy //-ehh- es //-ehh- estuve /saliendo con una tica que / he conocido desde / desde el lunes / del Cuartel // fuimos // ayer y también hoy a / a almorzar / y ella me dijo al empie al principio de la de la del almuerzo que sí / que mañana ella no pueda salir conmigo pero con mucho gusto viernes vamos a Heredia a / descubrir una nueva discoteca / que yo no / conoce // y estuve muy alegre porque todavía no no conozco con / no nunca salió en en //nunca salí en Heredia /y ella me dijo 'sí vamos a ahí // con con mi carro' y todo perfecto //y después sí almorzamos y todo fue muy lindo y después del almuerzo ////-ahh- caminamos // has hasta el carro de ella en San José // de San Pedro hasta San José / y al final ella me dijo 'es que M... / ahhh- -ehh- se me fue pero //-ahh- yo tengo un / tengo un muy bue grande trabajo que necesita hacer para la universidad /hasta lunes /-ehhh- entonces no tengo tiempo / para / salir con usted viernes pero / voy a ver usted el // sábado' / y yo me enojó / ten / yo me enojé / tan un poco porque /antes como una hora antes ella me dijo 'sí que claro vamos' y después ella me dijo que no. 
HN: ajá

HNN: esa fue / la última / experiencia que me recuerdo muy bien.

1. Resumen: no hay.

2. Orientación:

a) Temporal: el día de la cita: 'hoy'.

b) Personajes: el narrador y una muchacha costarricense.

c) Información adicional: había conocido a la joven el lunes anterior en un bar.

3. Evaluación: Es también el resultado de la historia: "yo me enojé".

4. Secuencia de eventos:

a) Salieron a almorzar.

b) Ella le dijo que iban a salir el viernes a Heredia.

c) Él se sintió muy alegre de saber que iba a conocer un nuevo lugar.

d) Almorzaron y todo fue muy lindo.

e) Después del almuerzo, caminaron hacia el carro de ella.

f) Ella le dice que tiene que presentar un trabajo para la universidad y que se le había olvidado, por lo que no tiene tiempo para salir con él el viernes.

5. Resultado: él se enojó un poco.

6. Coda: esa es la última experiencia de enojo que recuerda.

Como se puede ver, la secuencia de esta narración es totalmente clara y presenta todas las partes fundamentales. La historia también incluye todos los argumentos correspondientes al sentimiento en cuestión ${ }^{6}$. Asimismo, el manejo de los tiempos del mundo narrado es adecuado.

\subsection{La historia de emoción del HNN 5}

e. HNN: -emm- / miedo // -emm- por ejemplo / cuando yo tuvía / muchos dolores / $\mathrm{amm} /$ una vez / en mi /go / ¿cómo?

HN: garganta

HNN: gargante/ yo / tuve mucho miedo que / es una enfermedad muy // -emmm- muy grave

HN: ujú

HNN: pero / finalmente / no / -emm- todo está bien

HN: ¿y qué era?

HNN: -emm- / como una infección / solo

1. Resumen: no hay.

2. Orientación:

a) Temporal: una vez que tenía dolor de garganta.

3. Evaluación: "tuve mucho miedo"

4. Secuencia de acontecimientos:

a) Ella tuvo miedo de que se tratara de una enfermedad grave.

5. Resultado: al final todo estaba bien, era solamente una infección. 
6. Coda: no hay.

Esta hablante cumple con los requisitos mínimos para el relato, pero es bastante escueta en la orientación y la secuencia de eventos. La narración, por consiguiente, se escucha muy simple. También incluye los argumentos para referirse a la emoción, pero no se explica mucho la situación.

\subsection{La historia de emoción del HNN 6}

f. HNN: culpa / sí / cuando yo es/ estaba en Nueva Zelanda ////-emm- sí / yo escribía poco // a mis papás y todo // y / un año después me /// por eso / eso / me dio mucha culpa / o yo sentía mucha culpa después

HN: ¿pero ellos se enojaron? [se dice mientras el HNN sigue hablando]

HNN: en Nueva Zelanda no / [se dice al mismo tiempo de la intervención anterior del $\mathrm{HN}]$ pero / sí ellos se enojaron mucho

$\mathrm{HN}$ : ¿y por qué no les escribías?

HNN: porque // no tenía gana ganas de escribir y / no puedo escribir muy bien / ah / puedo escribir pero / no puedo concentrarme en / en una carta o algo y sentarme por / no sé media hora para escribir una carta

HN: ajá ajá ¿y ahora en Costa Rica ha sido lo mismo entonces también?

HNN: yo escribo en correos electrónicos / más fe / más fácil

HN: ya ajá ¿en eso momento no tenías...?

HNN: y yo tengo un problema / es que / no quiero escribir algo y / yo sé que // en una semana /mi pensamientos o mis senti sentimientos cambian // pero la carta / llega a / Alemania /// o tarda una semana en llegar a Alemania y ///

HN: entonces...

HNN: entonces //-ahh- ya mis pensamientos / mis sentimientos / han cambiado

HN: ujú ujú ujú

1. Resumen: no hay.

2. Orientación:

a) Espacial: cuando estaba en Nueva Zelanda.

b) Personajes: el narrador y sus padres.

c) Información adicional: Este hablante proporciona mucha información como una forma de justificar el hecho de no escribir mucho: no tenía ganas de escribir porque no puede concentrarse en una carta por mucho tiempo. Le resulta más fácil escribir correos electrónicos. No le gusta escribir cuando sabe que la carta va a tardar mucho en llegar a su destino, pues sus sentimientos y sus pensamientos cambian.

3. Evaluación: "yo sentía mucha culpa después"

4. Secuencia de sucesos:

a) El narrador no escribía mucho.

b) Sus padres se enojaron. 
5. Resultado: Se deduce que el resultado es que sintió culpa porque sus padres se enojaron.

6. Coda: no hay.

Este hablante también es bastante escueto en su historia, aunque esta presenta la estructura básica y es muy clara. La justificación que da para no escribir se presenta en forma ordenada y suple de alguna manera la falta de acontecimientos del relato. Su uso de los tiempos del mundo narrado es adecuado, así como los argumentos para la emoción de culpa.

\subsection{La historia de emoción del HNN 7}

g. HNN: cuando ///// mi / hermano /// construía / su casa / y / yo le /// ayudaba // construyéndola //// -ehh- / me enojaba que // para él / era ///// -ehh- cierto // que // yo le / ayudo / que / yo // yo le / ayudé / mucho / y a veces faltaba // la gracias o //

HN: ya

HNN: agradecerme / cosas así

HN: él asumía que usted lo iba a hacer y ya

HNN: sí

HN: ajá

HNN: era como / por supuesto él es mi hermano y / 'hágalo'

HN: ajá ajá

HNN: y lo hice pero /// no me gustaba mucho

HN: ujú

HNN: me enojó / con él

1. Resumen: no hay.

2. Orientación:

a) Tiempo: cuando su hermano construía una casa.

b) Personajes: el narrador y su hermano.

3. Evaluación: "me enojó con él"

4. Secuencia de acontecimientos:

a) Él le ayudaba a su hermano a construir la casa.

b) Para su hermano era seguro que él le iba a ayudar.

c) El narrador le ayudó mucho.

d) Su hermano no le daba las gracias.

5. Resultado: el narrador se enojó.

6. Coda: no hay.

En general, esta historia cumple con la organización básica, pero prácticamente emplea en la secuencia de eventos únicamente el pretérito imperfecto. Esto da la sensación de que la historia no avanza, no hay ningún punto, todo parece información de fondo. La historia finaliza sin que se perciba que pasó algo relevante, a pesar de que también se encuentran los argumentos propios del sentimiento de enojo. 


\subsection{La historia de emoción de la HN}

h. HN1: Bueno de miedo / la que más me acuerdo fue en el terremoto de hace diez años porque les tengo pánico pánico pánico a los a los temblores y después de después de del bueno en realidad del primero que yo me acuerdo y que sentí así pánico era cuan / diay yo tenía como siete años / que fue en el del ochenta y tres y estaba con mi mamá donde mi abuela y entonces cuando empezó a temblar / que era de noche / que era en una Semana Santa / la cerca de la casa de mi abuela era de zinc / entonces se movía para atrás y para adelante y se hacía para todo lado y parecía que se iba a caer y mi abuela se puso a llorar y ahí a rezar en medio patio y abrazándonos a las dos y y nunca nunca en la vida yo me acordaba de haber sentido un un temblor / entonces cuando fue el de / después de ahí les agarré pánico / más por lo de la bendita cerca y todavía yo me acuerdo cómo sonaba la cerca moviéndose y todo /y después de ahí //les les cogí pánico y en el del noventa y uno yo pasé como // dos o tres semanas sin dormir

NN2: jumm

NN1: pasaba toda la noche ahí viendo para el techo y yo ya veía la hora en que /;de verdad! [se dirige a un tercero presente] la hora en que en que ya ya se venía un temblor y todavía ahora / todavía ahora yo escucho los / los perros que empiezan a ladrar y los gatos que empiezan o las cucarachas que comienzan a salir y ya yo empiezo 'va a temblar / va a temblar / va a temblar' y no duermo ¿verdad? ¿cierto? [se dirige a un tercero presente] // no duermo / un día que estaban los perros ahí aullando haciendo un escándalo y $\mathrm{F}$ me dijo /'va a pasar algo' porque / había [risas] / porque había temblado ese día en la mañana / no pude dormir en toda la noche // de miedo / cualquier temblor así fuerte que me acuerde sobre todo esos dos.

1. Resumen: La experiencia de miedo que más recuerda se refiere al terremoto de hace diez años.

2. Orientación:

a) Tiempo: en 1983, cuando tenía siete años.

b) Espacio: la casa de la abuela.

c) Personajes: la narradora, su abuela y su madre.

d) Elementos de ambientación: era de noche, Semana Santa.

e) Información adicional: les tiene pánico a los temblores.

3. Evaluación: "les agarré pánico (a los temblores)".

4. Secuencia de eventos:

a) Empezó a temblar.

b) La cerca de la casa se movía y parecía que se iba a caer.

c) Su abuela se puso a llorar y a rezar.

d) Su abuela las abrazó.

5. Resultado: ahora siente pánico por los temblores y se acuerda de todo lo que pasó.

6. Coda: cualquier terremoto fuerte le provoca miedo.

Narración intercalada:

1. Orientación:

a) Tiempo: 1991 . 
2. Evaluación: sintió pánico.

3. Eventos:

a) Se deduce que tembló.

4. Resultado:

a) No pudo dormir en tres semanas. Cuando cree que va a temblar se asusta mucho, no puede dormir.

Como se puede observar, la complejidad narrativa de la HN es mucho mayor, pues incluso interpola una segunda narración que refuerza el sentimiento de la primera y se percibe como una consecuencia de esta. Cumple con todas las partes de la historia y la secuencia de eventos es muy clara, además de que introduce todos los aspectos de orientación que podrían ser necesarios. También incluye los elementos importantes para referirse a la emoción respectiva y su manejo de los tiempos del mundo narrado es totalmente adecuado, como se esperaría de un hablante nativo.

\section{Correspondencias entre la calidad narrativa y la percepción de la competencia del narrador}

Al observar el resultado de la evaluación ${ }^{8}$, vemos que los HNN 2, 4 y 6 obtuvieron las calificaciones más altas $(5,75 ; 5,66$ y 5,83, respectivamente). El HNN1 también se acerca a este puntaje $(5,16)$. Los cuatro presentaron narraciones muy bien estructuradas, con la orientación necesaria y la secuencia de acontecimientos bien organizada. Asimismo, hicieron un uso adecuado de los tiempos del mundo narrado e incluyeron en sus relatos los argumentos necesarios asociados a cada emoción. Por su parte, los HNN $3(3,91), 5(4,16)$ y $7(3,75)$ recibieron los puntajes más bajos. El HNN3 no pudo contar la historia con suficiente claridad y, aunque presenta las partes básicas, no es muy evidente cuál es la secuencia de los acontecimientos. Además, confundió los argumentos de la emoción de su relato y la parte de orientación hizo perder el hilo de los eventos. La HNN5 fue muy escueta en los sucesos y la orientación, y tampoco suplió esta falta con comentarios adicionales de ningún tipo. Sin embargo, obtuvo la quinta calificación, pues su narración está bien estructurada. El HNN7 fue el más bajo. Su historia se quedó prácticamente en la relación de eventos de segundo plano y la secuencia en cuanto al hilo narrativo no existe, es decir, parece no haber trama. De la misma manera, hizo un mal uso de los tiempos del mundo narrado.

Los HNN que se acercan más a la complejidad narrativa del relato de la $\mathrm{HN}$ son los HNN 1 y 4.

Si partimos de que existe una tendencia a utilizar oraciones más complejas cuando describimos emociones negativas y esto se emplea como una clave para el oyente para detectar la afectación del hablante, pues, cuanto más elaboradas son las unidades de la narración, más impacto emocional logra el relato (Rintell 1990: 81, 84), comprendemos mejor el resultado de la evaluación. Según Rintell (1990), los hablantes más fluidos en su estudio son los que cuentan una narración más compleja (en cuanto a la organización estructural expuesta) y es más probable que sean juzgados como mejores hablantes de inglés. 
Los discursos deben ser no solamente cohesivos, sino también coherentes. En la coherencia, los conceptos y las relaciones entre las partes de la historia deben ser relevantes entre sí y para el conjunto, con el fin de permitirle al oyente hacer inferencias plausibles sobre el significado. Partiendo de esta idea, se puede afirmar que la historia del HNN3 no es coherente, pues no parece haber una relación clara entre las partes ni se aprecia la relevancia de la sección de información, por lo que el hacer inferencias sobre el significado de la historia resulta difícil.

En términos de interés provocado por las historias en los oyentes que las calificaron, cabe mencionar que estos consideraron que las narraciones de los HNN 1, 2, 4 y 6 resultaban interesantes, mientras que las de los HNN 3, 5 y 7 eran aburridas. Si se recuerda el tema de cada relato (HNN1: sus problemas para subir una montaña; HNN2: cuando una de sus pacientes trató de apagar una luz eléctrica soplándola; HNN3: el proceso de entrada al ejército; HNN4: su relación con una costarricense y lo que sintió cuando esta le canceló una cita; HNN5: una vez que sintió un dolor de garganta fuerte; HNN6: el porqué no le gusta escribir cartas; HNN7: cuando le ayudó a su hermano a construir una casa y no recibió las gracias), podríamos tratar de inferir cuáles narraciones resultarían normalmente más "interesantes": una situación graciosa como la de la HNN2, y una situación con un hilo narrativo muy claro sobre una relación de pareja, como la del HNN4. Son menos interesantes los relatos de los HNN 3 y 7, pues en estos en realidad no pasa nada: el HNN3 se queda en la parte de explicaciones de fondo y su historia no tiene ni una línea de sucesos que llevan a una resolución ni un tema bien definido; el HNN7 cuenta una situación en la que tampoco pasa nada, todos los acontecimientos se narran como parte de un segundo plano (especialmente por su uso de los tiempos del mundo narrado) y no hay una situación conflictiva. Las historias de los HNN 1 y 6 presentan una serie de acontecimientos, con una situación conflictiva clara y esto las vuelve "más interesantes". El relato de la HNN5 es muy simple y esto la ubica entre las menos interesantes.

\section{Más allá de la gramática en la clase de español como segunda lengua}

Tradicionalmente en la enseñanza del español como segunda lengua en Costa Rica, el centro de atención en las clases ha estado en la exposición detallada y explícita de reglas gramaticales, con la consecuente práctica de las estructuras morfosintácticas que se estén estudiando en el momento, para luego, una vez realizado esto, continuar con otro tema gramatical. La clase, por consiguiente, tiene como fin primordial el control del componente morfosintáctico, y parte del supuesto de que un tema explicado implica que los estudiantes ya lo dominan, lo pueden emplear en forma comunicativamente efectiva, pueden comprender las emisiones dirigidas a ellos que contengan dichas estructuras, y sabrán utilizarlas en los contextos discursivos, sociales y estilísticos adecuados. En consecuencia, por lo general, pecamos de ser demasiado pretenciosos en relación con los logros que se pueden desprender del tratamiento tradicional de la gramática en la clase de L2.

Ocupándonos de la narración de eventos en pasado, la clase de español como L2 normalmente no estaría estructurada a partir de la relación de experiencias personales echando mano de diversos recursos lingüísticos, sino a partir de la explicación de la formación del pretérito perfecto simple y del pretérito imperfecto de indicativo y sus respectivos usos, aislándolos de los contextos en los que aparecen y explicándolos mediante oraciones. ¿Qué pasa, 
entonces, con el valor discursivo de estos tiempos? Como tiempos del mundo narrado, estas dos formas se presentan, principalmente, siempre que contamos un relato, y alternan para indicar cuál información proporcionada en la narración es de primer plano (acontecimientos que hacen avanzar la historia, eventos en secuencia) y cuál de segundo plano (escenografía de la historia, información adicional). Al realizar las prácticas orales, se espera que los estudiantes manejen en forma discursivamente correcta algo que se ha explicado en forma descontextualizada a partir de reglas independientes. Por ejemplo, al pedírsele a un estudiante adulto que narre cómo era su niñez o alguna anécdota de su juventud, como una forma de practicar la oposición pretérito simple/imperfecto, se espera que este produzca un discurso narrativo adecuado en cuanto al uso de ambos tiempos, sin que se haya tratado en la clase este tema desde un punto de vista narrativo. Además, se pone un énfasis especial en la corrección de las estructuras gramaticales, sin evaluar cuál es el fin último de contar una historia.

Es claro que la narración del HNN4 (ejemplo d) es estructuralmente más organizada que la del HNN3 (ejemplo c), a pesar de sus varios errores en la morfología verbal y otros problemas de morfosintaxis. Sin embargo, es percibido como un hablante competente y fluido, además de ser considerado un buen orador (Sánchez 2001). Por el contrario, el HNN7 es considerado poco fluido poco competente en el manejo de la lengua y un mal narrador. De lo anterior se desprende que lo más importante, en cuanto a la percepción de los HN en lo concerniente al habla de los HNN, es el cumplimiento exitoso de la tarea narrativa y no la ausencia total de errores gramaticales.

Un método sencillo de tratar el valor discursivo de los tiempos del mundo narrado en la clase es tomar una narración pequeña y separar los verbos que expresan los acontecimientos que hacen avanzar la historia de los verbos que sirven de orientación narrativa. Obsérvese el ejercicio con la historia de la HN (ejemplo h) estudiada en este trabajo.

El hilo narrativo de la historia es el siguiente:

- El temblor fue en el 83

- Empezó a temblar

- La abuela de la narradora se puso a llorar

- La narradora les agarró pánico a los temblores

Alrededor de estos hechos se encuentra la ambientación de la historia:

La narradora tenía siete años / estaba con su mamá y su abuela / era de noche / era Semana Santa / la cerca era de cinc / la cerca se movía / la cerca parecía que se iba a caer.

De esta forma, queda claro cuál es el valor que cumplen el pretérito simple y el imperfecto dentro de cualquier narración: indicar si la información es de primer o de segundo plano. 


\section{Conclusiones}

Como se demostró en un estudio sobre la percepción de la fluidez en español como L2 (Sánchez 2001), los aspectos que conforman el mensaje no solo no se dan en forma aislada, sino que tampoco se perciben desligados unos de otros. Si, por razones metodológicas, se debe segmentar la lengua y enseñarla por partes, también se deben crear espacios donde se practique como un todo. La meta, entonces, será centrar la práctica en cómo lograr determinados objetivos y valernos de los recursos de que dispongamos para tal efecto. En este sentido, el énfasis de la práctica será, por ejemplo, "hablar sobre momentos en que nos hemos sentido tristes, felices, enojados" y para tal efecto emplear, como un recurso lingüístico entre muchos otros, el pretérito imperfecto y el pretérito perfecto simple en sus valores narrativos. Claro está, un énfasis no implica abandonar el otro, sino darle mayor relevancia a emplear diversas estrategias (ya sean gramaticales, narrativas, estilísticas, léxicas, gestuales, sociolingüísticas, pragmáticas, etc.) con la mira puesta en un objetivo primordial: comunicarnos efectivamente, y, en otras ocasiones, ocuparnos de la enseñanza de elementos separados de gramática o pronunciación y llevar a cabo prácticas focalizadas acerca del tema en cuestión.

\section{Notas}

1. Para los criterios para seleccionar a los informantes y el corpus analizado, véase Sánchez 2001.

2. Ténganse en cuenta, para los fines de este trabajo, las siguientes convenciones de transcripción: /: pausa de 1 segundo o menos; //: pausa de 1-2 segundos; ///: pausa de 2-3 segundos; ////: pausa de 3-5 segundos; ////: pausa de más de 5 segundos. Una exposición detallada de las narraciones y una transcripción pormenorizada se pueden encontrar en Sánchez 2001.

3. "La percepción de un peligro o la anticipación de un mal posible provoca un sentimiento desagradable, acompañado de deseos de huida” (Marina 1999: 438).

4. "El cumplimiento de un deseo provoca un sentimiento positivo, acompañado de sosiego" (Marina 1999: 442).

5. "Un individuo hace una acción que considera mala porque hace daño a otra persona o porque contraviene sus creencias o las normas morales de su sociedad. Una vez realizada la acción siente un malestar que le hace desear no haberla hecho o poder reparar la falta." (Marina 1999: 370). La culpa es una interiorización de la vergüenza, el que la experimenta es víctima y juez al mismo tiempo.

6. "La percepción de un obstáculo, ofensa o molestia breve, pasajero y/o injustificado provoca un sentimiento negativo de irritación y un movimiento contra el causante" (Marina 1999: 436). El protagonista se siente ofendido o maltratado e interpreta lo que pasa y lo que se le dice como una demostración de poca estima hacia él.

7. El pánico es un sentimiento de terror, un miedo muy intenso (Marina 1999). Tiene los mismos argumentos que el miedo, pero la intensidad es mayor.

8. Los resultados de la evaluación corresponden al cálculo del promedio ponderado de los puntajes asignados por los doce jueces. 


\section{Bibliografía}

Alarcos Llorach, Emilio. 2000. Gramática de la lengua española. Madrid: Espasa Calpe.

Andersen, Elaine et al. (Eds.). 1990. Developing communicative competence in a second language. Massachusetts: Heinle Publishers.

Bernstein Ratner, Nan y Jean Berko Gleason (Eds.). 1999. Psicolingüística. Madrid: McGrawHill/Interamericana de España.

Bonvillain, Nancy. 1993. Language, Culture and Communication. The Meaning of Messages. New Jersey: Prentice Hall.

Brown, Gullian y George Yule. 1993. Análisis del discurso. Madrid: Visor Libros.

Jaworski, Adam y Nikolas Coupland. 1999. The Discourse Reader. New York: Routledge.

Labov, William. 1999. “The transformation of experience in narrative”. En: Jaworski (Ed.).

Marina, José Antonio y Marisa López Penas. 1999. Diccionario de los sentimientos. Barcelona: Anagrama.

McCabe, Allyssa. 1999. "Oraciones combinadas: texto y discurso". En: Bernstein (Ed.).

Rintell, Ellen M. 1990. "That's incredible: stories of emotion told by second language learners and native speakers". En: Andersen (Ed.).

Sánchez Avendaño, Carlos. 2001. La percepción de la fluidez en español como segunda lengua. Tesis de Maestría: Universidad de Costa Rica.

Weinrich, Harald. 1968. Estructura y función de los tiempos en el lenguaje. Madrid: Gredos. 